\title{
New technique for using SMES to limit fault currents in wind farm power systems
}

\author{
Mariam E.Elshiekh, Diaa-EldinA. Mansour, Senior Member, IEEE, Min Zhang,WeijiaYuan, Haigang Wang and Min \\ Xie
}

\begin{abstract}
This paper introduces a new scheme which uses a multifunctional superconducting device that can be used as an energy storage and as afault current limiter. It is denoted as superconducting magnetic energy storage - fault current limiter (SMES-FCL) and is modeled as a number of pancakes. It is connected to a wind turbine power system via tertiary transformer and power converters. A complete control scheme is built to achieve effective power transfer between the superconducting coil and the power system during normal operation to smooth the wind turbine output power. The fault current limiting function is implemented using a new technique that inserts a few pancakes from the whole SMES coil into the main electrical system during the fault and isolates the remaining pancakes. The number of pancakes used to limit the fault is quenched and operates as a resistive fault current limiter. The whole system including the wind turbine, the SMES-FCL model and the interface circuit are implemented using PSCAD/EMTDC computer package. Also, the control scheme of SMES-FCL is built based on a feedback current signal to enable its operation into the two modes.
\end{abstract}

Index Terms-Wind turbine generators, superconducting coil, magnetic energy storage, fault current limiter.

\section{INTRODUCTION}

$\mathrm{E}$ nergy plans for many countries for the next years include a large increase in the share of renewable power tion to the total power generation. This comes with the trends of mitigating global warming and environmental pollution in addition to reducing fossil fuel consumption. Among various types of renewable power generation, wind energy is the est growing renewable energy source [1].

However, integrating wind energy has many challenges to power system operators like output power fluctuations [2] and sensitivity to grid disturbances. These challenges become more prominent with induction generators based wind turbines

This work was supported from the British Council through Newton Fund 216435894 and Newton-Mosharafa PhD scholarship program between Egyptian government and British council.

Mariam Elshiekh, Min Zhang and Weijia Yuan are with the Department of Electronic and Electrical Engineering, University of Bath, Bath BA2 7AY,

U.K. (e-mail: M.E.M.Elshiekh@bath.ac.uk; M.Zhang2@bath.ac.uk; W.Yuan@bath.ac.uk)

Diaa-Eldin A. Mansour is with the Department of Electrical Power and Machines Engineering, Faculty of Engineering, Tanta University, Tanta 31521, Egypt (e-mail: mansour@f-eng.tanta.edu.eg)

Haigang Wang and Min Xie are with Anhui Electric Power co., State Grid of China (email: wanghg03@126.com; xiem261x@ah.sgcc.com.cn )
[3]. The power fluctuations may cause subsequent frequency fluctuations at the grid and reduce the whole system stability. Also, with increased share of wind power generation into the grid, wind farms must act like conventional generators. Wind turbines must support reactive power to the grid when needed and support the grid during voltage dips. Accordingly, wind turbinesmust be kept connected to the grid during grid disturbances [4], especially with large sharing.

During the last years, superconducting materials have emerged in many applications. They offer unique performance, compact size and high efficiency [5]. Due to their advantages over other types of electrical appliances, superconducting devices played an important role in solving integration problems of wind farms.

Superconducting magnetic energy storage (SMES) systems can absorb or release power with ac systems via a power conditioner system within very short periods. It has a very high charge and discharge efficiency which reached above 95\% [6]. So, SMES systems can be used effectively to reduce output power fluctuations of wind farms and increase the stability of the power grid containing wind farms [7, 8]. In addition, superconducting fault current limiters (SFCL) proved very effective current limitation within few milliseconds [9-11]. This is achieved with self-operation mechanism and without adding additional resistance or losses during normal operation. So, SFCL could be successfully applied for fault response enhancement of wind turbines [12-14].

However, the main drawback of the superconducting devices is the high cost of the material itself. So, integrating two devices into one multi-functional device will be of great benefit as it will decrease the cost to benefit ratio of these devices.

This paper presents a new scheme to integrate the fault current limiting capability into the SMES system to improve the stability of a wind turbine system and to protect it during faults. The superconducting magnetic energy storage - fault current limiting (SMES-FCL) device uses the concept of resistive type fault current limiter by allowing a part of the superconducting coil to quench and change to resistive mode during the fault period. This process will limit the fault current without inserting the whole reactance of the superconducting coil that may have a negative impacton the system stability during faults. The wind turbine system was built and connected to the load, and then, the SMES-FCL system is connected to the power line with a tertiary transformer. The control algorithm was designed and simulated with the whole system using PSCAD/EMTDC computer package. 


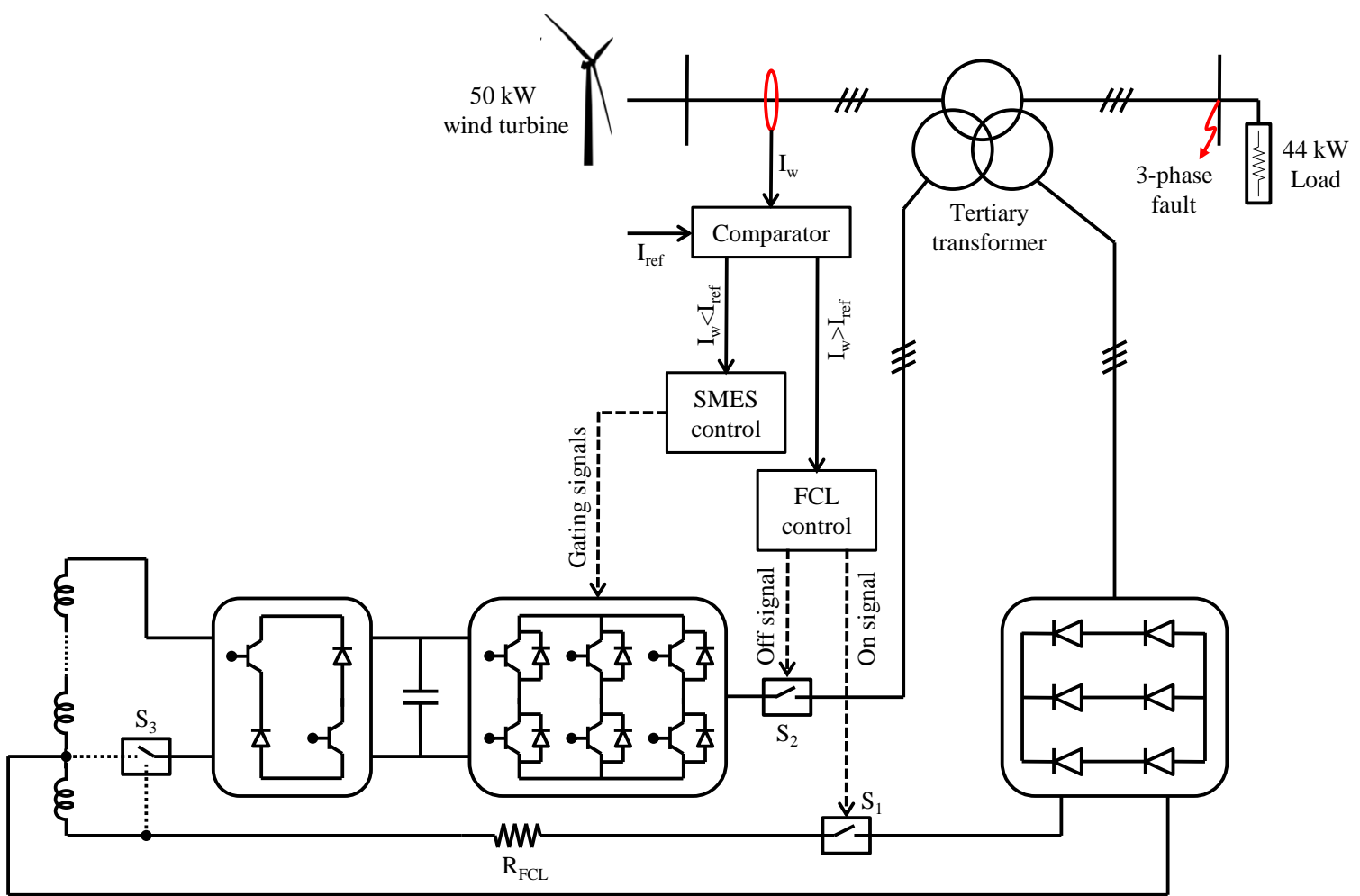

Fig. 1. Connection of the wind turbine with SMES-FCL system and load.

\section{SYSTEM DESCRIPTION}

The SMES-FCL system is tested using a wind turbine generator connected to the grid that is represented by a load as shown in Fig. 1. The SMES-FCL is connected to the power system using tertiary three phase transformer. The first windings are connected in series with the power line while the second windings are connected to a voltage source converter circuit ended by a DC-link capacitor. The superconducting coil (SC) is connected to the DC-link capacitor with a DC-DC converter. The third windings of the transformer are connected to a diode bridge, and then through a switch to a few pancakes of the superconducting coil.

The wind turbine generator is an induction generator type with a rating of $50 \mathrm{~kW}$ and $200 \mathrm{~V}$. The $\mathrm{SC}$ inductance is $0.5 \mathrm{H}$ and its rated current is $350 \mathrm{~A}$, which corresponds to an energy storage capability of $30 \mathrm{~kJ}$. The coil is considered to be made from YBCO material with copper stabilizer.

\section{SMES-FCL OPERATION}

\section{A. Energy storage part}

The control of the voltage source converter (VSC) depends on maintaining constant voltage and frequency at the connection point with the grid [15]. Firstly, the voltage and current values at the $\mathrm{AC}$ side of the transformer is measured. A phase locked loop (PLL) technique is used to hold the phase value (Theta) at each instant [16]. Then, the current reference values in the $d q$-frame are calculated based on the reference voltage and frequency. These values are used to determine the corresponding voltage reference values in the $d q$-frame. The injected voltage to the power system is calculated based on the difference between the actual values and the reference values in addition to Theta output from the PLL as shown in Fig. 2(a).

The PI controller parameters were chosen based on trial and error method.The upper arm parameters were set as:proportional gain $(\mathrm{P})=2$ and integral gain $(\mathrm{I})=0.5$, while the lower arm parameters are: $\mathrm{P}=1.5$ and $\mathrm{I}=0.5$. Finally, the VSC pulses are generated using space vector pulse width modulation technique (SVPWM).

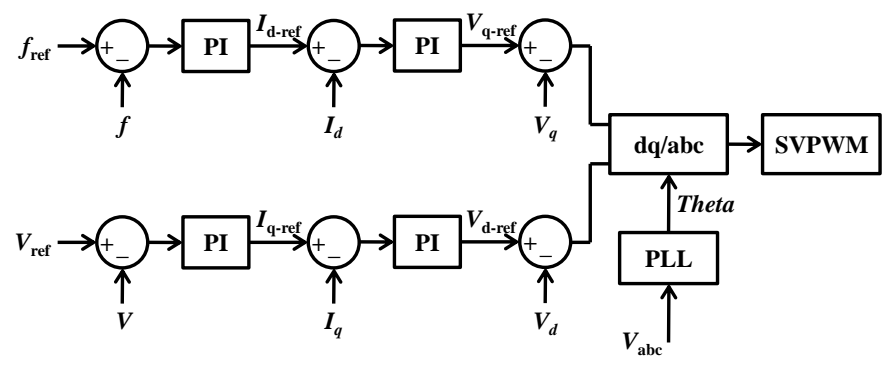

(a) Control scheme of VSC.



(b) Control scheme of DC-chopper.

Fig. 2. Control of energy storage part of SMES-FCL. 
On the other hand, the control objective of the DC-chopper is to maintain the DC-link voltage constant by charging or discharging the current of the SC coil to the capacitor or vice versa. The DC-chopper consists of two IGBTs and two diodes. Depending on the grid power and the DC-link voltage, the operation mode of the SC coil is determined. If the power generated is less than the reference power, the superconducting coil will discharge through the diodes to keep the voltage across the capacitor constant. When the generated power is higher than the reference, the two IGBTs is turned on and off to charge the coil. If there is no power difference, the coil current is circulated on one IGBT and one diode in order to keep coil energy without transferring power from/to the main system. The pulse generation technique used for both IGBTs of the DC-chopper is shown in Fig. 2(b). The Dc-link capacitor voltage is referred herein as $\left(V_{d c}\right)$, while its reference value is $\left(V_{\text {ref_dc }}\right)$. D1 is the duty cycle which determines the periods at which the IGBTs are set to be on or off. The PI parameters for the chopper controller are $\mathrm{P}=5$ and $\mathrm{I}=0.25$.

\section{B. Fault current limiting part}

The fault current limiting part is connected to the system via the third windings of thetertiary transformer as shown at Fig. 1. The transformer windings are connected to the SC coil with a normal bridge which consists of a six diodes. The main idea in limiting the fault current is to use the resistance provided by few pancakes of the SC coil after their quenching. The number of pancakes used for fault current limitation depends on the resistance required by the system during fault. Using fewpancakes enables to limit the fault current with reducing the inserted inductance during the fault period. During the fault, the remaining pancakes of the SC coil will be isolated and operated into freewheeling mode through switch $\left(\mathrm{S}_{3}\right)$ in order to keep their stored energy and protect them from quenching.

The limiting resistance of the SC coil during quenching is represented by a constant resistance connected in series with the diode bridge through a current controlled switch $\left(\mathrm{S}_{1}\right)$ that is triggered based on the current on the main power system. The other pancakes with the whole energy storage system are isolated during fault by turning off another current controlled switch $\left(\mathrm{S}_{2}\right)$ as shown in Fig. 1.

When the current decreases again lower than its critical value after fault clearance, the switch $S_{1}$ is re-opened and the switch $S_{2}$ is closed again to continue the energy storage function.

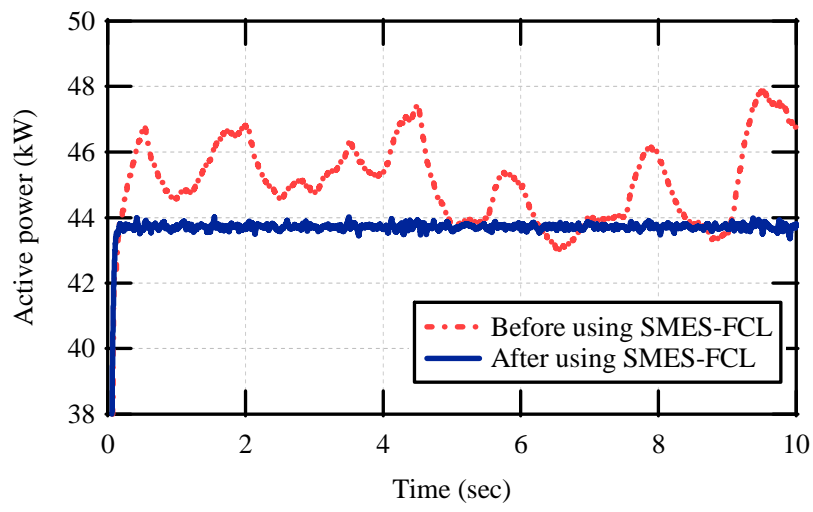

Fig. 3.Delivered nower to the load hefore and after using SMES-FCL.

\section{RESULTS AND DISCUSSION}

The new scheme is tested with the wind turbine system shown in Fig. 1. Firstly, smoothing the wind turbine output power is tested using the SMES-FCL system to ensure the energy storage function of the device. Then, a three phase to ground fault was applied at the load terminals to test the ability of SMES-FCL to limit the fault current to lower levels.

\section{A. Smoothing output power}

The first function of the SMES-FCL is to smooth output power from wind turbines under variable wind speed. Fig. 3 shows the output power from the wind generator after and before connecting SMES-FCL system. It is clear that the variable wind speed causes the output power to be fluctuating. This willcause frequency oscillations with a negative impact on the stability of the power system [17]. After using SMES-FCL, it is noted that SMES-FCL could effectively limit the fluctuations in the output power according to the reference value set by the operator. Smoothing output power mainly occurs by injecting or absorbing power to the power line, and thus, obtaining constant power delivered to the load side.

\section{B. Fault current limitation}

The current limitation value depends on the value of the resistance inserted during the fault period which consequently depends on the number of pancakes allowed to quench. Inserting many pancakes to the system will increase the limitation value, but on the other hand, it will increase the heat generated on the coil. Also, inserting many pancakes will increase the inductance inserted to the system during the fault with a negative impact on the system stability. So, a suitable value of li-

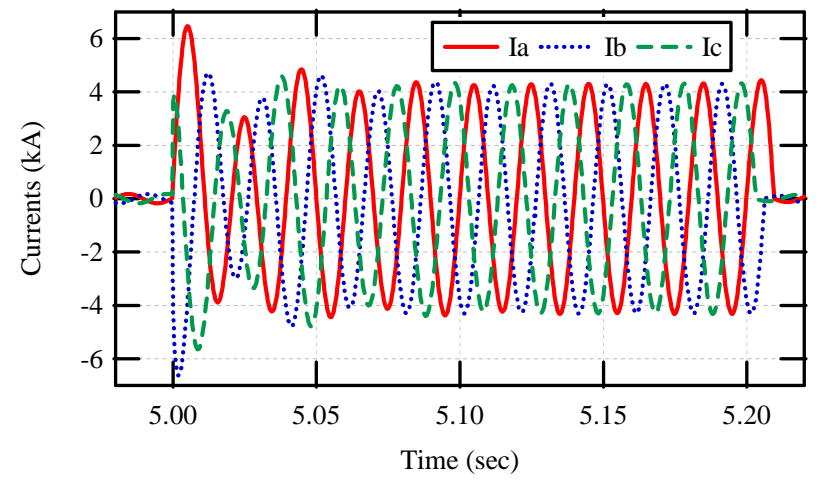

Fig. 4. Generator currents during fault without using SMES-FCL.

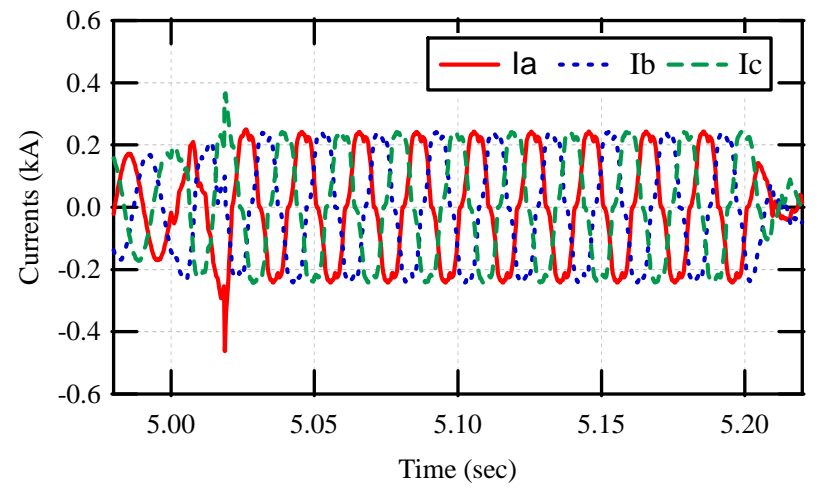

Fig. 5. Generator currents during fault with using SMES-FCL. 
miting resistance must be chosen to achieve the desired limitation without affecting the coil itself. In this study, a resistance value of $1 \Omega$ is used as the fault current limiting resistance. Considering YBCO material with copper stabilizer [18, 19], resistance value of $1 \Omega$ can be achieved using about $50 \mathrm{~m}$ length of superconducting tape. This length corresponds to about $15 \mathrm{mH}$ inductance, if it was wound in a single pancake structure of inner diameter of $10 \mathrm{~cm}$.

To test the current limiting ability of SMES-FCL, a three phase fault is applied at the load terminals from 5 to 5.2 seconds to ensure the operation with long fault periods. The generator currents are shown with and without connecting SMES-FCL on Fig. 4 and Fig. 5, respectively. Without using SMES-FCL, the current at the generator terminals reached 6 $\mathrm{kA}$ in the first peak of the fault and continues with more than $4 \mathrm{kA}$ during the remaining fault period. After connecting

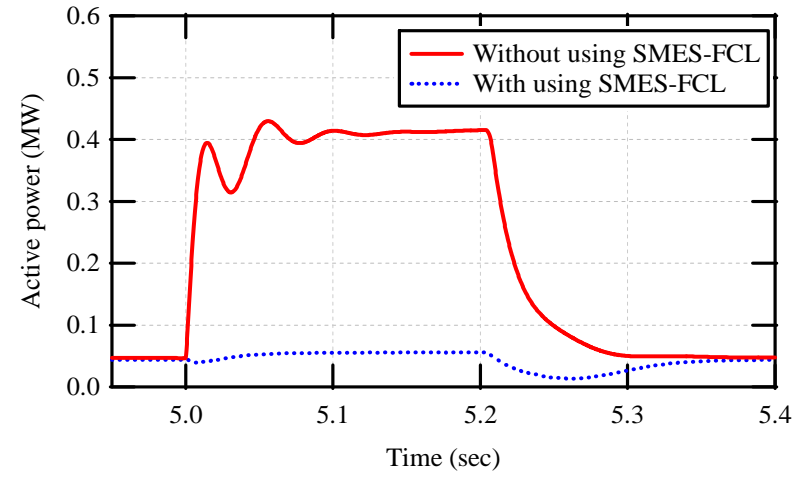

Fig. 6. Generator output power with and without using SMES-FCL.



Fig. 7. Generator output voltage without using SMES-FCL.

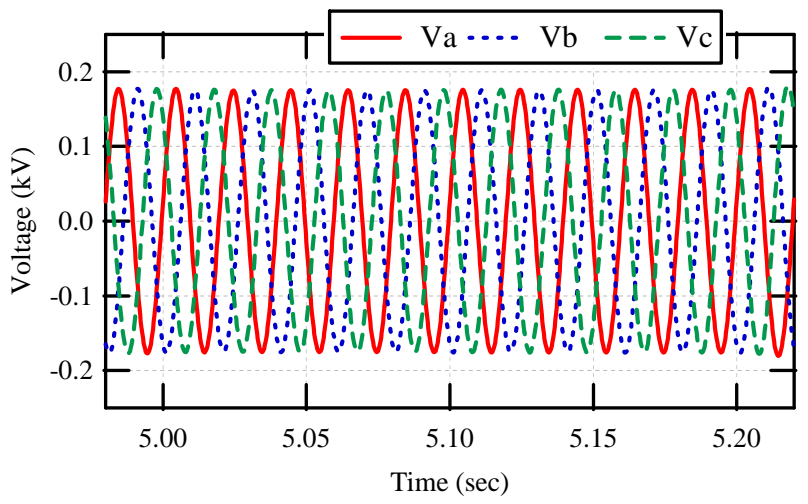

Fig. 8. Generator output voltage after using SMES-FCL.
SMES-FCL, the first peak of current was successfully limited to about $0.5 \mathrm{kA}$ and reached $0.23 \mathrm{kA}$ during the remaining fault period.

In addition, generated power during fault decreased from 0.4 MW without using SMES-FCL to less than 0.01 MW as shown in Fig. 6. This large reduction in generated power during fault enhances the stability of the generator and protects it from failure. The voltage at the generator terminals before and afterusing SMES-FCL is also illustrated in Fig.7 and Fig. 8, respectively. Without using SMES-FCL, the voltage during the fault period was dropped to an RMS value of about 0.035 $\mathrm{kV}$. This can affect the compliance of wind turbine with grid codes [20], causing the turbine to trip during the fault. After using the proposed scheme, the drop in the output voltage attained nearly zero, resulting inan improvement in the fault ride-through capability of the wind turbine generator and allowing it to be connected to the grid during grid faults.

\section{CONCLUSION}

This paper proposes a new scheme for SMES to operate with multi functions, either as a storage device or as a current limiting device. The proposed system,denoted as SMESFCL, was connected to a wind turbine power system via a tertiary transformer and power converters. The control system was developed considering the two functions. During normal operation, SMES-FCL was operated as energy storage allowing the fast transfer of the power between the superconducting coil and the ac power system. This enabled to smooth the output power from the wind turbine generator and improve the whole system stability.

During fault conditions, SMES-FCL was operated as a fault current limiter by inserting few pancakes using a proper control scheme and allowing them to quench during fault periods, while isolating the other pancakes. The limiting action enabled to limit the short circuit currents within the first peak of the fault and to keep the terminal voltage within acceptable values.This fast limitation enables to protect the wind turbine generator and other power system elements with a positive impact on the dynamic stability and compliance with grid codes of the whole system.

\section{REFERENCES}

[1] U.S. Energy Information Administration, International Energy Outlook 2016, 2016.

[2] J. Lin, Y. sun, Y. Song, W. Gao and P. Sorensen, "Wind power fluctuation smoothing controller based on risk assessment of grid frequency deviation in an isolated system,"IEEE Trans. Sustain. Energy, vol. 4, no. 2, pp. 379-392, April 2013.

[3] M. J. Hossain, H. R. Pota, M. A. Mahmud and R. A. Ramos, "Investigation of the impacts of large-scale wind power penetration on the angle and voltage stability of power systems,"IEEE Systems Journal, vol. 6, no. 1, pp. 76-84, March 2012.

[4] I. Erlich and F. Shewarega, "Insert impact of large-scale wind power generation on the dynamic behaviour of interconnected systems," 2007 iREP Symposium - Bulk Power System Dynamics and Control - VII. Revitalizing Operational Reliability, Charleston, USA, pp. 1-7, 2007.

[5] G. Angeli, M. Bocchi, M. Ascade, V. Rossi, A. Valzasina and L. Martini, "Development of superconducting devices for power grids in Italy: Update about the SFCL project and launching of the research activity on HTS cables," IEEE Trans. Appl. Supercond.,vol. 27, no. 4, pp. 1-6, June 2017. 
[6] J. Zhu, X. Bao, B. Yang, P. Chen, Y. Yang and M. Qiu, "Dynamic simulation test research on power fluctuation compensation using hybrid SMES of YBCO and BSCCO tapes,'IEEE Trans. Appl. Supercond., vol. 22, no. 3, Art. No. 5700404, June 2012.

[7] I. Ngamroo and T. Karaipoom, "Improving low-voltage ride-through performance and alleviating power fluctuation of DFIG wind turbine in DC microgrid by optimal SMES with fault current limiting function," IEEE Trans. Appl. Supercond.,vol. 24, no. 5, pp. 1-5, Oct. 2014.

[8] H. M. Hasanien, "A set-membership affine projection algorithm-based adaptive-controlled SMES units for wind farms output power smoothing," IEEE Trans. Sustain. Energy, vol. 5, no. 4, pp. 1226-1233, Oct. 2014.

[9] N. Y. Kwon, H. S. Kim, K. L. Kim, S. Hahn, H. -R, O.-B, H. M. Kim, W. S. Kim, C. Park, and H.G. Lee, "The effects of a stabilizer thickness of the YBCO coated conductor (CC) on the quench/recovery characteristics," IEEE Trans. Appl. Supercond., vol. 20, no. 3, pp. 1246-1249, June 2010

[10] S. Kar, S. Kulkarni, M. Dixit, K. P. Singh, A. Gupta, P. V. Balasubramanyam, S. K. Sarangi and V. V. Rao, "Study on recovery performance of high $\mathrm{T}_{\mathrm{c}}$ superconducting tapes for resistive type superconducting fault current limiter applications," Physics Procedia, vol. 36, pp. 1231-1235, 2012.

[11] D. A. Mansour and D. M. Yehia, "Analysis of 3-phase superconducting fault current limiters in power systems with inhomogeneous quenching," IEEE Trans. Appl. Supercond., vol. 23, no. 3, Art. No. 5602605, June 2013.

[12] L. Ye and L. Z. Lin, "Study of superconducting fault current limiters for system integration of wind farms," IEEE Trans. Appl. Supercond., vol. 20 , no. 3 , pp. $1233-1237$, June 2010
[13] M. E. Elshiekh, D. E. A. Mansour and A. M. Azmy, "Improving fault ride-through capability of DFIG-based wind turbine using superconducting fault current limiter," IEEE Trans. Appl. Supercond., vol. 23, no. 3, Art. No. 5601204, June 2013.

[14] Z. C. Zou, X. Y. Chen, C. S. Li, X. Y. Xiao and Y. Zhang, "Conceptual design and evaluation of a resistive-type SFCL for efficient fault ride through in a DFIG," IEEE Trans. Appl. Supercond., vol. 26, no. 1, Art. No. 5600209, Jan. 2016

[15] J. Li, M. Zhang, Q. Yang, Z. Zhang and W. Yuan, "SMES/battery hybrid energy storage system for electric buses,"IEEE Trans. Appl. Supercond.,vol. 26, no. 4, pp. 1-5, June 2016.

[16] A. M. Gee, F. Robinson and W. Yuan, "A superconducting magnetic energy storage-emulator/battery supported dynamic voltage restorer,"IEEE Trans. Energy Convers., vol. 32, no. 1, pp. 55-64, March 2017.

[17] Y. Liu, S. You and Y. Liu, "Study of wind and PV frequency control in U.S. power grids-EI and TI case studies," IEEE Power and Energy Technology Systems Journal, vol. 4, no. 3, pp. 65-73, Sept. 2017.

[18] H. I. Du, S. O. Heo, T. M. Kim, B. S. Han, J. H. Lee and S. C. Yang, "Effect on current-limiting performance of combining condition YBCO thin-film wire having different stabilization layer with superconducting fault current limiter using iron core and coils," IEEE Trans. Appl. Supercond.,vol. 24, no. 3, pp. 1-5, June 2014.

[19] S. Kar and V. V. Rao, "Comparative study on the fastest effective fault limitation for stabilized and stabilizer-free high $\mathrm{T}_{\mathrm{c}}$ superconductors,"Physica C: Superconductivity and its Applications, vol. 541, pp. 50-54, Oct. 2017.

[20] M. Tsili and S. Papathanassiou, "A review of grid code technical requirements for wind farms," IET Renew. Power Gener., vol. 3, pp. 308332, Sep. 2009 